\title{
The effect of ADHD on the life of an individual, their family, and community from preschool to adult life
}

\section{A Harpin}

Arch Dis Child 2005;90(Suppl I):i2-i7. doi: 10.1136/adc.2004.059006

Attention deficit/hyperactivity disorder (ADHD) may affect all aspects of a child's life. Indeed, it impacts not only on the child, but also on parents and siblings, causing disturbances to family and marital functioning. The adverse effects of ADHD upon children and their families changes from the preschool years to primary school and adolescence, with varying aspects of the disorder being more prominent at different stages. ADHD may persist into adulthood causing disruptions to both professional and personal life. In addition, ADHD has been associated with increased healthcare costs for patients and their family members.

Correspondence to: Dr V A Harpin, Ryegate Children's Centre, Sheffield Children's NHS Trust, Tapton Crescent Road, Sheffield S10 5DD UK; Val.Harpin@ sheffch-tr.trent.nhs.uk
A ttention deficit/hyperactivity disorder (ADHD) is a chronic, debilitating disorder which may impact upon many aspects of an individual's life, including academic difficulties, ${ }^{1}$ social skills problems, ${ }^{2}$ and strained parentchild relationships. ${ }^{3}$ Whereas it was previously thought that children eventually outgrow ADHD, recent studies suggest that $30-60 \%$ of affected individuals continue to show significant symptoms of the disorder into adulthood. ${ }^{4}$ Children with the disorder are at greater risk for longer term negative outcomes, such as lower educational and employment attainment. ${ }^{5}$ A vital consideration in the effective treatment of ADHD is how the disorder affects the daily lives of children, young people, and their families. Indeed, it is not sufficient to merely consider ADHD symptoms during school hours-a thorough examination of the disorder should take into account the functioning and wellbeing of the entire family.

As children with ADHD get older, the way the disorder impacts upon them and their families changes (fig 1). The core difficulties in executive function seen in $\mathrm{ADHD}^{7}$ result in a different picture in later life, depending upon the demands made on the individual by their environment. This varies with family and school resources, as well as with age, cognitive ability, and insight of the child or young person. An environment that is sensitive to the needs of an individual with ADHD and aware of the implications of the disorder is vital. Optimal medical and behavioural management is aimed at supporting the individual with ADHD and allowing them to achieve their full potential while minimising adverse effects on themselves and society as a whole.

The aim of this paper is to follow the natural history of this complex disorder through preschool years, school life, and adulthood and to consider its effect on the family, the community, and society as a whole. In addition, comorbidities and healthcare costs are examined.

\section{THE PRESCHOOL CHILD}

Poor concentration, high levels of activity, and impulsiveness are frequent characteristics of normal preschool children. Consequently, a high level of supervision is the norm. Even so, children with ADHD may still stand out. In this age group there is often unusually poor intensity of play and excessive motor restlessness. ${ }^{89}$ Associated difficulties, such as delayed development, oppositional behaviour, and poor social skills, may also be present. If ADHD is a possibility, it is vital to offer targeted parenting advice and support. Even at this early stage parental stress may be huge when a child does not respond to ordinary parental requests and behavioural advice. ${ }^{9}$ Targeted work with preschool children and their carers has been shown to be effective in improving parent child interaction and reducing parental stress. ${ }^{10}{ }^{11} \mathrm{~A}$ useful review of the available evidence and methods is provided by Barkley. ${ }^{12}$

\section{PRIMARY SCHOOL YEARS}

The primary school child with ADHD frequently begins to be seen as being different as classmates start to develop the skills and maturity that enable them to learn successfully in school. Although a sensitive teacher may be able to adapt the classroom to allow an able child with ADHD to succeed, more frequently the child experiences academic failure, rejection by peers, and low self esteem (fig 2). Comorbid problems, such as specific learning difficulties, may also start to impact on the child, further complicating diagnosis and management. Assessment by an educational psychologist may help to unravel learning strengths and difficulties, and advise on necessary support in the classroom.

Frequently, difficulties at home or on outings with carers (for example, when shopping, out in the park, or visiting other family members) also become more apparent at this age. Parents may find that family members refuse to care for the child, and that other children do not invite them to parties or out to play. Many children with ADHD have very poor sleep patterns, and although they appear not to need much sleep, daytime behaviour is often worse when sleep is badly affected. As a result, parents have little time to themselves; whenever the child is awake they have to be watching them. Not surprisingly,

Abbreviations: $\mathrm{CHQ}$, Child Health Questionnaire; $\mathrm{ODD}$, oppositional defiant disorder. 


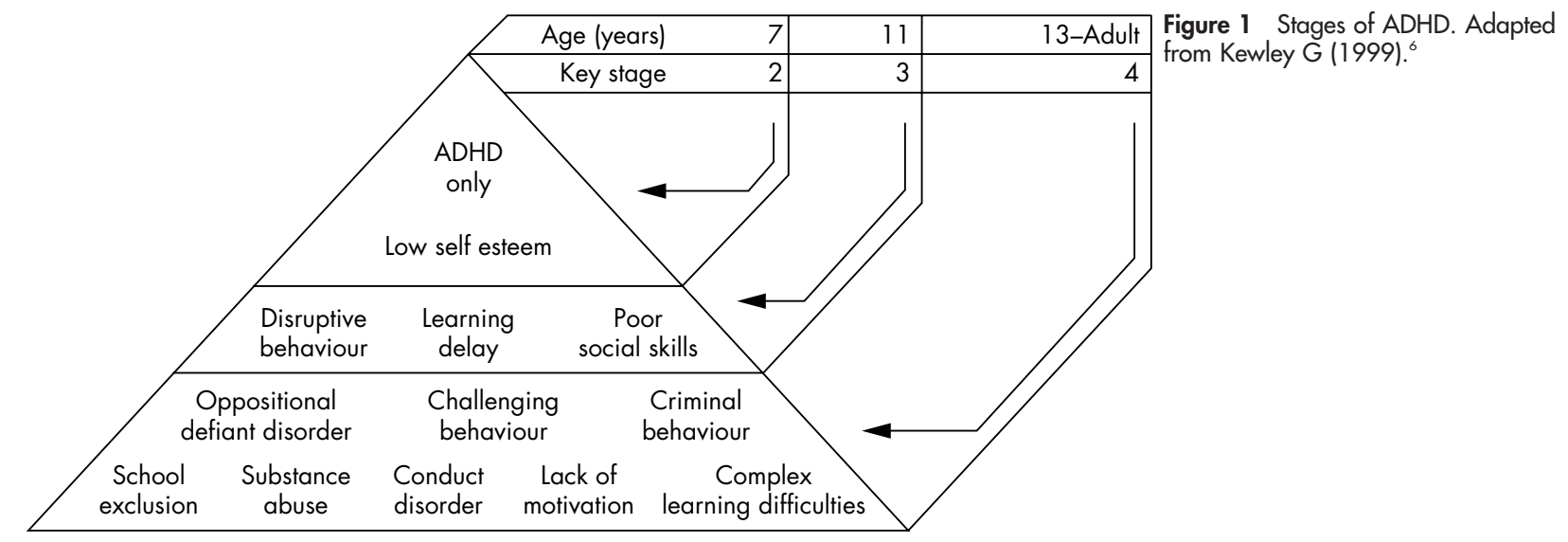

family relationships may be severely strained, and in some cases break down, bringing additional social and financial difficulties. ${ }^{14}$ This may cause children to feel sad or even show oppositional or aggressive behaviour.

Assessing the quality of life of the child suffering from ADHD is difficult. Behavioural assessments are usually carried out by parents, teachers, or healthcare professionals, and it can usually only be inferred how the child must feel. However, data from self evaluations indicate that children with ADHD view their most problematic behaviour as less within their control and more prevalent than children without ADHD. ${ }^{15}$ Participation in a school based, nurse led support group was associated with an increase in self worth in pre-adolescents with ADHD. ${ }^{16}$

Johnston and Mash reviewed the evidence of the effect of having a child with ADHD on family functioning. ${ }^{14}$ They concluded that the presence of a child with ADHD results in increased likelihood of disturbances to family and marital functioning, disrupted parent-child relationships, reduced parenting efficacy, and increased levels of parent stress, particularly when ADHD is comorbid with conduct problems.

In a survey of the mothers and fathers of 66 children, parents of children with ADHD combined and inattentive subtypes expressed more role dissatisfaction than parents of control children. ${ }^{17}$ Furthermore, ADHD in children was reported to predict depression in mothers. ${ }^{18}$ Pelham et al reported that the deviant child behaviours that represent major chronic interpersonal stressors for parents of ADHD children are associated with increased parental alcohol consumption. ${ }^{19}$

Limited attention has been given to sibling relationships in families with ADHD children. While it has been reported that siblings of children with ADHD are at increased risk for conduct and emotional disorders, ${ }^{20}$ a more recent study presenting sibling accounts of ADHD identified disruption caused by symptoms and behavioural manifestations of $\mathrm{ADHD}$ as the most significant problem. ${ }^{21}$ This disruption was experienced by siblings in three primary ways: victimisation, caretaking, and sorrow and loss. Siblings reported feeling victimised by aggressive acts from their ADHD brothers through overt acts of physical violence, verbal aggression, and manipulation and control. In addition, siblings reported that parents expected them to care for and protect their ADHD brothers because of the social and emotional immaturity associated with ADHD. Furthermore, as a result of the ADHD symptoms and consequent disruption, many siblings described feeling anxious, worried, and sad. ${ }^{21}$

Broader social and family functioning has been assessed using the Child Health Questionnaire (CHQ), a parent rated health outcome scale that measures physical and psychosocial wellbeing. ${ }^{22-24}$ The studies demonstrated that treatment of ADHD with atomoxetine, a new non-stimulant medication for $\mathrm{ADHD}$, resulted in improved perception of quality of life, with improvements being apparent in social and family functioning, and self esteem. Further research assessing the ongoing quality of life for the child and their family following multimodal input is urgently needed.

\section{ADHD IN YOUNG PEOPLE}

Adolescence may bring about a reduction in the overactivity that is often so striking in younger children, but inattention, impulsiveness, and inner restlessness remain major difficulties. A distorted sense of self and a disruption of the normal development of self has been reported by adolescents with ADHD. ${ }^{25}$ Furthermore, excessively aggressive and antisocial behaviour may develop, adding further problems (fig 3). A study by Edwards et $a l^{27}$ examined teenagers with ADHD and

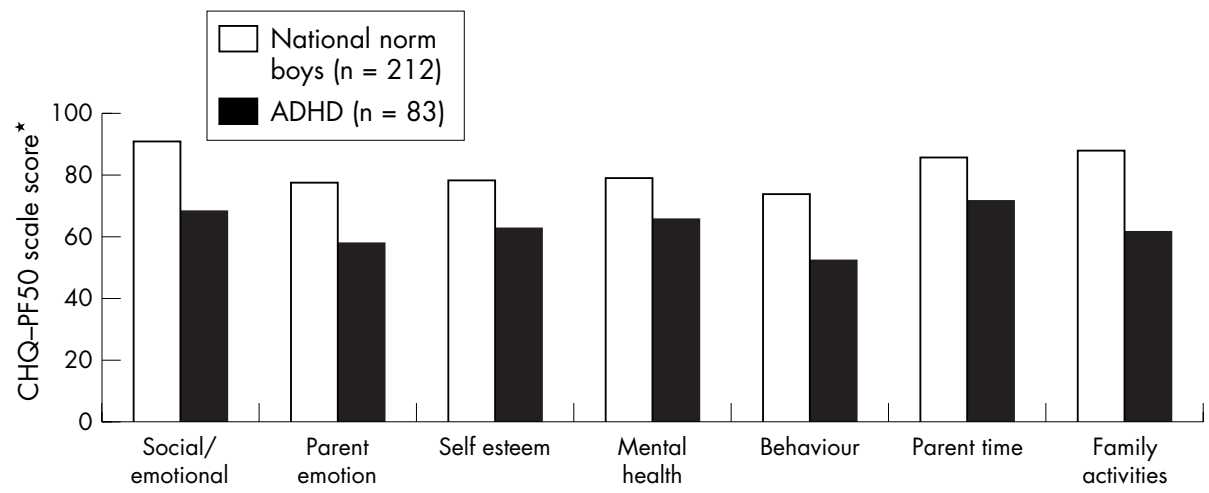

Figure 2 Emotional and family functioning in children with ADHD compared with controls. ${ }^{13}$ *Higher scores indicative of greater functioning. $\mathrm{CHQ}$, Child Health Questionnaire. ${ }^{13}$ 


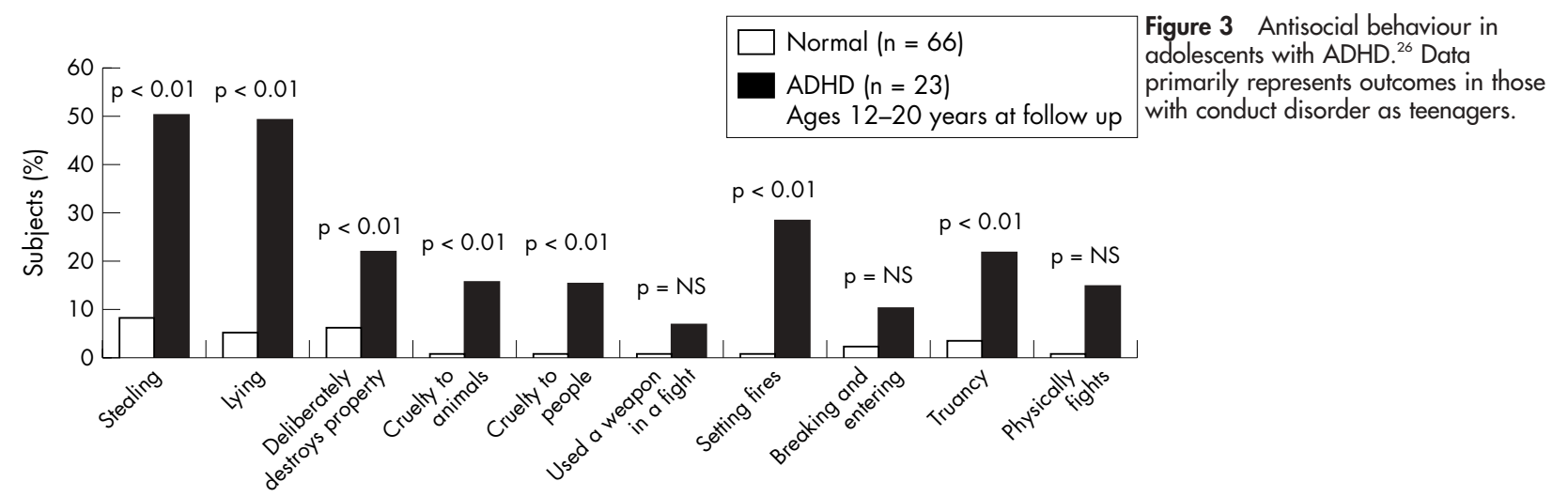

oppositional defiant disorder (ODD), which is defined by the presence of markedly defiant, disobedient, provocative behaviour and by the absence of more severe dissocial or aggressive acts that violate the law or the rights of others. These teenagers rated themselves as having more parent-teen conflict than did community controls. Increased parent-teen conflict was also reported when parents of teenagers with ADHD carried out the rating exercise. In addition, a survey of 11-15 year olds showed that those with hyperkinesis were twice as likely as the overall population to have "a severe lack of friendship". ${ }^{28}$

Young people with ADHD are at increased risk of academic failure, dropping out of school or college, teenage pregnancy, and criminal behaviour (fig 4A and B). Driving poses an additional risk. Individuals with ADHD are easily distracted from concentrating on driving when going slowly, but while driving fast may also be dangerous. It has been shown that, compared with age matched controls, drivers with ADHD are at increased risk of traffic violations, especially speeding, and are considered to be at fault in more traffic accidents, including fatal ones (fig 5)..$^{30}$ The risk of such events was increased further by the presence of concomitant ODD. ${ }^{29}$ However, it has been suggested that treatment may have a positive effect on driving skills. ${ }^{31}$

\section{ADULT LIFE}

As many as $60 \%$ of individuals with ADHD symptoms in childhood continue to have difficulties in adult life. ${ }^{32}{ }^{33}$
Adults with ADHD are more likely to be dismissed from employment and have often tried a number of jobs before being able to find one at which they can succeed. ${ }^{5}$ They may need to choose specific types of work and are frequently self employed. In the workplace, adults with ADHD experience more interpersonal difficulties with employers and colleagues. Further problems are caused by lateness, absenteeism, excessive errors, and an inability to accomplish expected workloads. At home, relationship difficulties and break-ups are more common. The risk of drug and substance abuse is significantly increased in adults with persisting ADHD symptoms who have not been receiving medication. ${ }^{34}$ The genetic aspects of ADHD mean that adults with ADHD are more likely to have children with ADHD. This in turn causes further problems, especially as the success of parenting programmes for parents of children with ADHD is highly influenced by the presence of parental ADHD. ${ }^{35}$ Thus, ADHD in parents and children can lead to a cycle of difficulties.

\section{COMORBIDITIES}

Comorbid disorders may impact on individuals with ADHD throughout their lives. It is estimated that at least $65 \%$ of children with ADHD have one or more comorbid conditions. ${ }^{36}$ The reported incidence of some of the most frequent comorbidities is shown in figure 6, with neurodevelopmental problems, such as dyslexia and developmental coordination disorder, being particularly common. Many children with ADHD also suffer from tic disorders (not related to stimulant
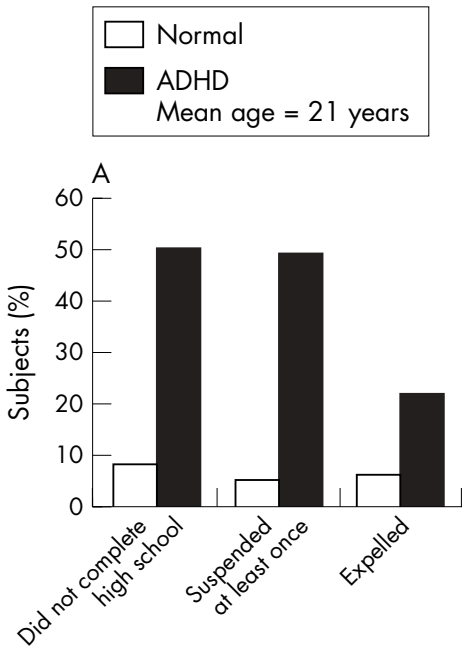
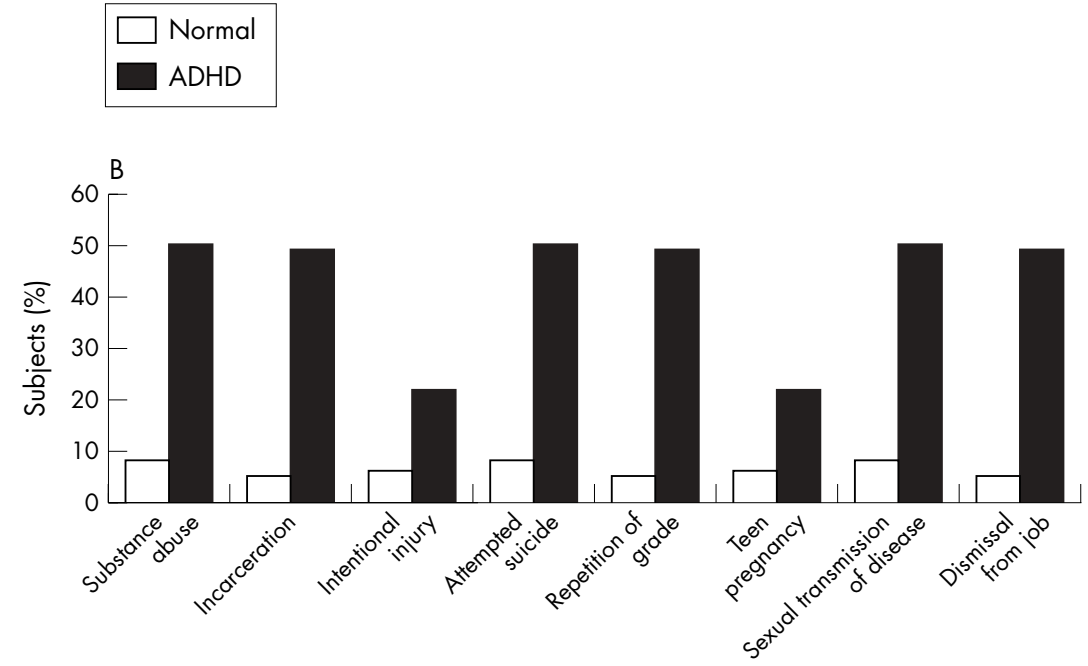

Figure 4 Impact of ADHD in adolescence. Data from Barkley RA; ${ }^{26}$ (A) Impact at school; (B) impact on health, social, and psychiatric wellbeing. 


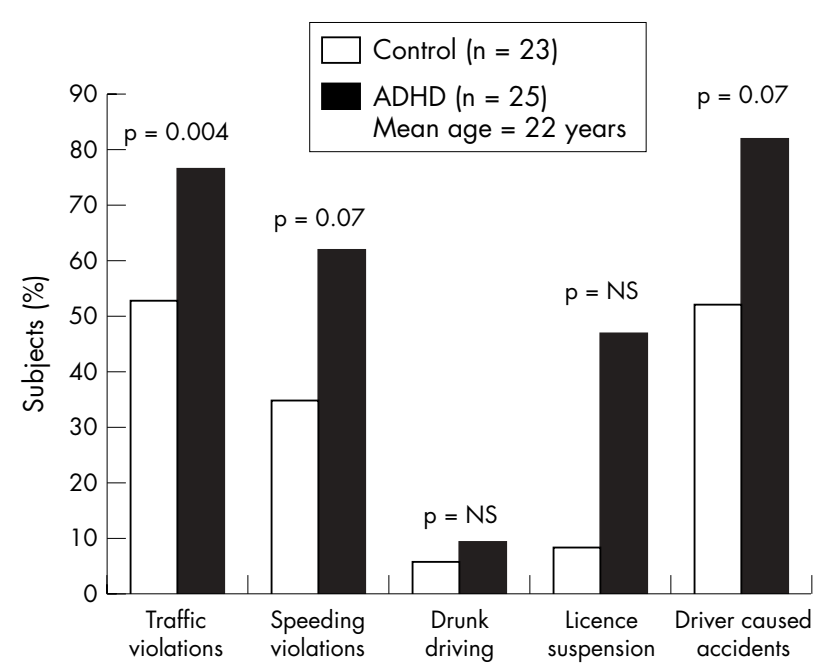

Figure 5 Driving-related offences in young adults with $A D H D$ and controls. NS, not significant. Data from Barkley RA et al. ${ }^{29}$

medication). In addition, around $60 \%$ of children with Tourette's Syndrome fulfil criteria for ADHD, ${ }^{38}{ }^{39}$ and autistic spectrum disorder is increasingly recognised with comorbid ADHD. ${ }^{39}$ Initially, excessive hyperactivity may mask the features of autistic spectrum disorder until the child receives medication. Conduct disorder and ODD coexist with ADHD in at least $30 \%$, and in some reports up to $90 \%$, of cases. ${ }^{36}$ These most frequently occurring comorbidities can, however, be considered more as complications of ADHD, with adversity in their psychological environment possibly determining whether children at risk make the transition to antisocial conduct. $^{40}$

\section{PROBLEMS ASSOCIATED WITH TREATMENT}

Growth deficits in children receiving stimulant treatment for ADHD have long been the subject of scientific discussion. Conflicting results have been reported with some authors indicating that stimulants do indeed affect growth in children, ${ }^{41-43}$ but that this only occurs during active treatment phase and does not compromise final height. ${ }^{44}$ Other studies, however, have not found any evidence to suggest that stimulants influence growth. ${ }^{45} 46$ Taken together, the results suggest that clinicians should monitor the growth of hyperactive children receiving stimulants, and consider dose reduction in individual cases should evidence of growth suppression occur.

Another frequently quoted concern about treatment of ADHD with stimulant medications is that it could lead to drug addiction in later life. Young people with ADHD are by nature impulsive risk takers, and there is clear evidence that untreated ADHD-especially with concomitant conduct disorder-is associated with a three- to fourfold increase in the risk of substance misuse. ${ }^{47}{ }^{48}$ In contrast, patients medicated with stimulants have a similar risk of substance misuse to controls. ${ }^{49}$ These data therefore provide strong evidence in favour of careful treatment and support for young people with ADHD.

\section{HEALTHCARE COSTS}

Healthcare costs for individuals with ADHD in the UK have not been fully estimated, but evidence from the USA suggests that they are increased compared with age matched controls. A population based, historical cohort study followed 4880 individuals from 1987 to 1995 and compared the nine year median medical cost per person: ADHD medical costs were US\$4306, whereas non-ADHD medical costs were US\$1944

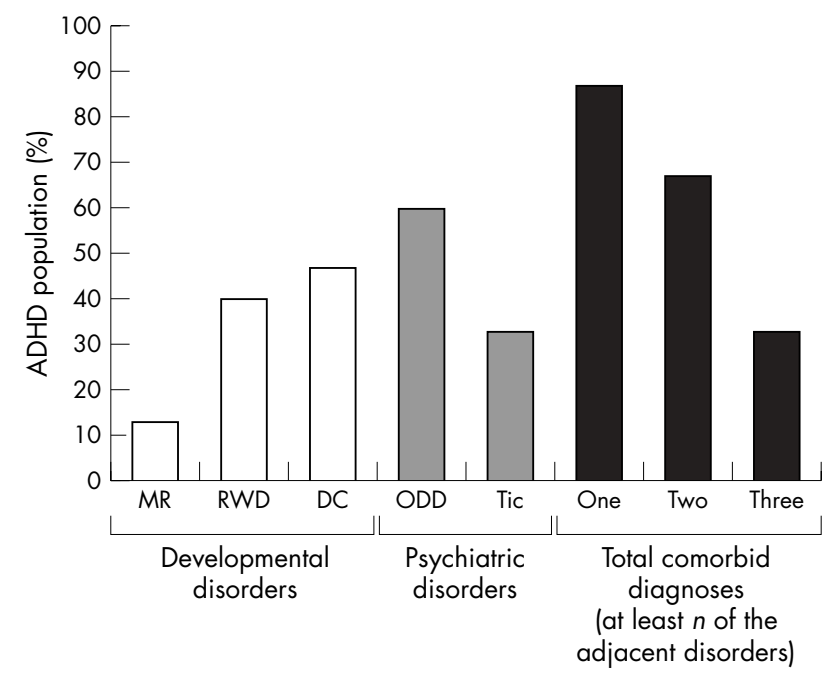

Figure 6 ADHD and comorbidity in Swedish school age children. ${ }^{37} \mathrm{MR}$, mental retardation; RWD, reading/writing disorder; DC, developmental coordination; ODD, oppositional defiant disorder.

$(p<0.01) .^{50}$ These findings are likely to reflect increased injury following accidents and a rise in use of substance abuse services and other outpatient facilities, although poor ability to comply with advice on medication (for example, asthma management) may also be implicated. A study of the injuries to children with ADHD established that children with ADHD were more likely to be injured as pedestrians or bicyclists than children not suffering from ADHD. They were more likely to sustain injuries to multiple body regions, head injuries, and to be severely injured. ${ }^{51}$ ADHD has been found to represent a risk factor for substance abuse, ${ }^{47}{ }^{52}$ and an investigation of prevalence of ADHD among substance abusers has established that ADHD was significantly overrepresented among inpatients with psychoactive substance use disorder. ${ }^{53}$ Increased use of health services is also seen in the relatives of individuals with ADHD. A study has shown that direct and indirect medical costs were twice as high as those of family members of a control group. ${ }^{54}$ The difference in these costs was primarily due to a higher incidence of mental health problems in the family members of ADHD patients, which reflects the increased stresses and demands of living with an adult or child with ADHD. Indeed, ADHD related family stress has been linked to increased risk of parental depression and alcohol related disorders. ${ }^{55-57}$

It is vital to consider the role of treatment of ADHD in decreasing the individual's risk of adverse outcomes. A number of studies on the effect of treatment of ADHD on the risk of substance abuse encouragingly demonstrate a fall in risk to that of the normal population..$^{58-60}$

\section{CONCLUSION}

Mannuzza's review of the long term prognosis in ADHD concludes that childhood ADHD does not preclude high educational and vocational achievements (for example, Master's degree or medical qualification). ${ }^{61}$ However, ADHD is a disorder that may affect all aspects of a child's life. Careful assessment is paramount, and if this demonstrates significant impairment as a result of ADHD, there is clear evidence that treatment of ADHD should be instituted. ${ }^{62}{ }^{63}$ Current treatment focuses mainly on the short term relief of core symptoms, mainly during the school day. This means that important times of the day, such as early mornings before school and evening to bedtime, are frequently unaffected by current treatment regimes. This can negatively 
impact on child and family functioning and fail to optimise self esteem and long term mental health development.

In 2003, the American Academy of Pediatrics recommended that clinicians should work with children and their families to monitor the success (or failure) of treatment, using certain criteria to assess specific areas of difficulty and quality of life as a whole. ${ }^{64}$ There has been a reluctance in the UK to treat ADHD with medication, fuelled by concerns about possible over-prescription in the USA. In addition, newspaper and media coverage of ADHD is often negative and stigmatising. The evidence of potentially severe difficulties for the child, the family, and, in some cases, for society as a whole, means that coordinated multi-agency effort to support the child and family is essential. Moreover, healthcare professionals have an important role in providing balanced and supportive information about ADHD and meeting the needs of affected individuals and their families.

\section{REFERENCES}

1 Faraone SV, Biederman J, Monuteaux MC, et al. A psychometric measure of learning disability predicts educational failure four years later in boys with ADHD. J Atten Disord 2001;4:220-30.

2 Bagwell CL, Molina BS, Pelham WE, et al. ADHD and problems in peer relations: Predictions from childhood to adolescence. J Am Acad Child Adolesc Psychiatry 2001;40:1285-92.

3 Johnston C, Mash EJ. Families of children with ADHD: review and recommendations for future research. Clin Child Fam Psychol Rev 2001;4:183-207.

4 Weiss G, Hechtman L. Hyperactive children grown up: ADHD in children, adolescents and adults. New York: Guildford, 1993.

5 Mannuzza S, Klein RG, Bessler A, et al. Adult outcome of hyperactive boys. Educational achievement, occupational rank and psychiatric status. Arch Gen Psychiatry 1993;50:565-76.

6 Kewley GD. Attention deficit hyperactivity disorder: Recognition, reality and resolution. London: David Fulton Publishers, 1999.

7 Barkley RA. Behavioral inhibition, sustained attention, and executive functions: constructing a unifying theory of ADHD. Psychol Bull 1997; 121:65-94.

8 Alessandri SM. Attention, play, and social behaviour in ADHD preschoolers. J Abnorm Child Psychol 1992;20:289-302.

9 DuPaul GJ, McGoey KE, Eckert TL, et al. Preschool children with attentiondeficit/hyperactivity disorder: impairments in behavioural, social, and school functioning. J Am Acad Child Adolesc Psychiatry 2001;40:508-15.

10 Sonuga-Barke EJ, Daley $D$, Thompson $M$, et al. Parent-based therapies for preschool attention-deficit/hyperactivity disorder: a randomised, controlled trial with a community sample. J Am Acad Child Adolesc Psychiatry 2001;40:402-8.

11 Barton J. PhD Thesis. The effect of modifying maternal expressed emotion on outcome of preschool hyperactivity. University of Glasgow, 2002.

12 Barkley R. Psychosocial treatments for attention-deficit/hyperactivity disorder in children. J Clin Psychiatry 2002;63:36-43.

13 Landgraf JM, Abetz L, Ware JE. The CHQ User's Manual, 2nd edition. Boston: HealthAct, 1999.

14 Johnston C, Mash EJ. Families of children with attention-deficit/hyperactivity disorder: review and recommendations for future research. Clin Child and Fam Psychol Rev 2001;4:183-207.

15 Kaidar I, Wiener J, Tannock R. The attributions of children with attentiondeficit/hyperactivity disorder for their problem behaviors. J Atten Disord 2003;6:99-109.

16 Frame K, Kelly L, Bayley E. Increasing perceptions of self-worth in preadolescents diagnosed with ADHD. J Nurs Scholarsh 2003;35:225-9.

17 Podolski CL, Nigg JT. Parent stress and coping in relation to child ADHD severity and associated child disruptive behaviour problems. J Clin Child Psychol 2001;30:503-13.

18 Faraone SV, Biederman J, Chen WJ, et al. Genetic heterogeneity in attention deficit hyperactivity disorder (ADHD): gender, psychiatric comorbidity, and maternal ADHD. J Abnorm Psychol 1995; 104:334-45.

19 Pelham WE Jr, Lang AR. Can your children drive you to drink? Stress and parenting in adults interacting with children with ADHD. Alcohol Res Health 1999;23:292-8.

20 Szatmari P, Offord DR, Boyle MH. Ontario Child Health Study: prevalence of attention deficit disorder with hyperactivity. J Child Psychol Psychiatry 1989;30:219-30.

21 Kendall J, Siblings accounts of attention deficit hyperactivity disorder. Family Proc 1999;38:1 17-36.

22 Michelson D, Faries D, Wernicke J, et al. Atomoxetine in the treatment of children and adolescents with attention-deficity/hyperactivity disorder: a randomised, placebo-controlled, dose response study. Pediatrics 2001;108:1-9.

23 Barton J, Prasad S, Buitelaar JK, et al. 10-week, open-label, acute treatment with atomoxetine in non-North American children with ADHD. Poster presented at the Royal College of Psychiatrists Annual General Meeting Edinburgh, UK, 30 June-3 July, 2003.
24 Harpin V. Changes in quality of life in patients with attention-deficithyperactivity disorder after atomoxetine treatment. Paper presented at the meeting of the European Academy of Childhood Disability (EACD). Norway: Oslo, 2-4 October, 2003.

25 Krueger $M$, Kendall J. Descriptions of self: an exploratory study of adolescents with ADHD. J Child Adolesc Psychiatr Nurs 2001;14:61-72.

26 Barkley RA. Attention deficit hyperactivity disorder: A handbook for diagnosis and treatment, 2nd edition. New York: Guildford Press, 1998.

27 Edwards G, Barkley RA, Laneri M, et al. Parent-adolescent conflict in teenagers with ADHD and ODD. J Abnormal Child Psychology 2001;29:557-72.

28 Meltzer H, Gatward R, Goodman R, et al. The mental health of children and adolescents in Great Britain. Office for National Statistics, London: The Stationery Office, 2000.

29 Barkley RA, Guevremont DC, Anastopoulos AD, et al. Driving-related risks and outcomes of attention deficit hyperactivity disorder in adolescents and young adults: A 3 to 5 year follow up survey. Pediatrics 1993;92:212-18.

30 Barkley RA, Murphy KR, Kwasnik D. Motor vehicle driving competencies and risks in teens and young adults with attention deficit hyperactivity disorder. Pediatrics 1996:98:1089-95.

31 Cox DJ, Merkel RL, Penberthy JK, et al. Impact of methylphenidate delivery profiles on driving performance of adolescents with attention-deficit/ hyperactivity disorder: a pilot study. J Am Acad Child Adolesc Psychiatry, 2004;43:269-75.

32 Weiss G, Hechtman L, Milroy T, et al. Psychiatric status of hyperactives as adults: a controlled prospective 15-year follow-up of 63 hyperactive children. $J$ Am Acad Child Psychiatry 1985;24:21 1-20.

33 Weiss M, Hechtman L, Weiss G. ADHD in Adulthood-A guide to current theory, diagnosis and treatment. Baltimore: Johns Hopkins University Press, 1999.

34 Biederman J, Wilens TE, Mick E, et al. Does attention-deficit hyperactivity disorder impact the development course of drug and alcohol abuse and dependence? Biol Psychiatry 1998;44:269-73.

35 Sonuga-Barke EJ, Daley D, Thompson M. Does maternal ADHD reduce the effectiveness of parent training for preschool children's ADHD? J Am Acad Child Adolesc Psychiatry 2002;41:696-702.

36 Biederman J, Newcom J, Sprich S. Comorbidity of attention deficit hyperactivity disorder with conduct, depressive, anxiety and other disorders. Am J Psychiatry 1991;148:564-77.

37 Kadesjo B, Gillberg C. The comorbidity of ADHD in the general population of Swedish school-age children. J Child Psychol Psychiatry 2001;42:487-92.

38 Freeman RD, Fast DK, Burd L, et al. An international perspective on Tourette syndrome: selected findings from 3,500 individuals in 22 countries. Dev Med Child Neurol 2000;42:436-47

39 Gillberg C, Gillberg IC, Rasmussen P, et al. Co-existing disorders in ADHDimplications for diagnosis and intervention. Eur Child Adolesc Psychiatry 2004;13(Suppl 1):180-92.

40 Taylor E. Clinical foundations of hyperactivity research. Behav Brain Res 1998;94:11-24.

41 Mattes JA, Gittelman R. Growth of hyperactive children on maintenance regimen of methylphenidate. Arch Gen Psychiatry 1983;40:317-21.

42 Lisska MC, Rivkees SA. Daily methylphenidate use slows the growth of children: a community based study. J Pediatr Endocrinol Metab 2003;16:711-18.

43 Poulton A, Cowell CT. Slowing of growth in height and weight on stimulants: a characteristic pattern. J Paediatr Child Health 2003;39:180-5.

44 Klein RG, Mannuzza S. Hyperactive boys almost grown up. III. Methylphenidate effects on ultimate height. Arch Gen Psychiatry 1988;45:1131-4.

45 Spencer T, Biederman J, Wilens T. Growth deficits in children with attention deficit hyperactivity disorder. Pediatrics 1998;102:501-6.

46 Biederman J, Faraone SV, Monuteaux MC, et al. Growth deficits and attention-deficit/hyperactivity disorder revisited: impact of gender, development, and treatment. Pediatrics 2003;111:1010-16.

47 Biederman J, Wilens TE, Mick E, et al. Does attention-deficit hyperactivity disorder impact the developmental course of drug and alcohol abuse and dependence? Biol Psychiatry 1998;44:269-73

48 Wilens TE. Impact of ADHD and its treatment on substance abuse in adults. J Clin Psychiatry 2004;65(Suppl 3):38-45.

49 Biederman J, Wilens T, Mick E, et al. Pharmacotherapy of attention-deficit/ hyperactivity disorder reduces risk for substance use disorder. Pediatrics 1999; 104:e20.

50 Leibson CL, Katusic SK, Barbaresi WJ, et al. Use and costs of medical care for children and adolescents with and without attention-deficit/hyperactivity disorder. JAMA 2001;285:60-6.

51 DiScala C, Lescohier I, Barthel $M$, et al. Injuries to children with attention deficit hyperactivity disorder. Pediatrics 1998;102:1415-21.

52 Sullivan MA, Rudnik-Levin F. Attention deficit/hyperactivity disorder and substance abuse. Diagnostic and therapeutic considerations. Ann N Y Acad Sci 2001;931:251-70.

53 Schubiner H, Tzelepis A, Milberger S, et al. Prevalence of attention-deficit/ hyperactivity disorder and conduct disorder among substance abusers. J Clin Psychiatry 2000;61:244-51.

54 Swensen AR, Birnbaum HG, Secnik K, et al. Attention-deficit/hyperactivity disorder: increased costs for patients and their families. J Am Acad Child Adolesc Psychiatry 2003;42:1415-23.

55 Cunningham CE, Benness BB, Siegel LS. Family functioning, time allocation, and parental depression in the families of normal and ADHD children. J Clin Child Psychol 1988;17:169-77. 
56 Brown RT, Pacini JN. Perceived family functioning, marital status, and depression in parents of boys with attention deficit disorder. J Learn Disabil 1989;22:581-7.

57 Hankin CS. ADHD and its impact on the family. Drug Benefit Trends 2001; 13(Suppl C):15-16.

58 Huss $M$, Lehmkuhl U. Methylphenidate and substance abuse: a review of pharmacology, animal and clinical studies. J Atten Disord 2002;6(Suppl 1):S65-71.

59 Faraone SV Wilens T. Does stimulant treatment lead to substance use disorders? J Clin Psychiatry 2003;64(Suppl 1):9-13.

60 Mannuzza S, Klein RG, Moulton JL 3rd. oes stimulant treatment place children at risk for adult substance abuse? A controlled, prospective follow-up study. J Child Adolesc Psychopharmacol 2003; 13:273-82

61 Mannuzza S, Klein RG. Long-term prognosis in attention-deficit/hyperactivity disorder. Child Adolesc Psychiatr Clin N Am 2000;9:711-26.

62 National Institute for Clinical Excellence (NICE). Guidance on the use of methylphenidate (Ritalin, Equasym) for attention deficit/hyperactivity disorder (ADHD) in childhood. Health Technology Assessment No 13, October, 2000

63 The MTA Cooperative Group. A 14-month randomised clinical trial of treatment strategies for attention-deficit/hyperactivity disorder. Arch Gen Psychiatry 1999;56:1073-86.

64 American Academy of Pediatrics, Reiff MI, Tippins S. ADHD-A Complete and Authoritative Guide. Chicago: Independent Publishers Group, 2003. 